\title{
Stratigraphic correlation of wells using discrete wavelet transform with fourier transform and multi-scale analysis
}

\author{
V. Srivardhan
}

Received: 14 March 2015/Accepted: 23 March 2016/Published online: 16 April 2016

(C) Springer International Publishing Switzerland 2016

\begin{abstract}
Stratigraphic correlation of wells involves correlation of stratigraphic interfaces which should be continuous across the area between the wells. Stratigraphic correlation of wells comes at an advanced stage of reservoir estimation, where accurate quantitative information is required for prospect evaluation of the target reserve. It requires input from a variety of geophysical surveys ranging from seismic surveys to core analysis. In this work a novel and innovative technique using discrete wavelet transform with fourier transform and multi-scale analysis is demonstrated, which can be utilized for detecting stratigraphic interfaces and correlating them between wells. The technique was first tested on synthetic gamma ray logs for two synthesized wells and was then applied to the well data taken from geophysical surveys undertaken by dGB Earth Sciences in the Netherlands Offshore F3 Block. Discrete wavelet transform and fourier transform was applied to gamma ray logs to identify potential interfaces and then multi-scale analysis was used to characterize each horizon by finding its fractal dimension. Interfaces which had similar lithology and thickness, had similar fractal dimensions and were therefore correlated. This approach was also compared with conventional wavelet based techniques and was proved to be
\end{abstract}

V. Srivardhan $(\bowtie)$

Department of Applied Geophysics, Indian School of

Mines, Dhanbad 826004, India

e-mail: vardhan.sri@gmail.com superior. The well correlation was also independently verified by identifying marker beds using seismic data in between the wells, and there was good agreement between the results that were obtained.

Keywords Well logging - Stratigraphic correlation . Stratigraphic interfaces $\cdot$ Wavelet transform $\cdot$ Multiscale analysis

\section{Introduction}

Well logging is a very important technique for reservoir characterization and has been in use since Conrad and Marcel Schlumberger first tested this technique in the year 1912, for the iron mines located in Normandy, France. This technique involves measuring the geophysical properties of the subsurface and translating the log response to determine the variations in the petrophysical properties in the subsurface. These include finding volume of clay, lithology, grain size, water saturation, porosity and permeability, all of which are essential for reservoir characterization. Various log responses exist, and the commonly used $\operatorname{logs}$ are sonic $\log$, self potential $\operatorname{logs}$, gamma ray logs, and resistivity logs. The subsurface is sampled very densely, with a resolution as low as $0.1 \mathrm{~m}$ and therefore gives an excellent structural and stratigraphic mapping of the subsurface. Using the petrophysical parameters the estimation of the intended 
reservoir extent and pay thickness is characterized, which could be for either hydrocarbons or minerals, and plays a crucial role in their production (Ellis 1987).

The log responses can be used to obtain stratigraphic information of the reservoir (Igbokwe 2011; Li et al. 2014; Mory and Iasky 1996). The self potential and gamma ray logs are used for stratigraphic interpretation as they are good lithology indicators and based on the log responses, the depositional environment ranging from deltaic and fluvial setting to clastic marine can be interpreted. The transgressive and regressive facies change can also be identified in the depositional environment from the $\log$ responses. A bell shaped response of either of the log responses indicates a transgressive environment. A funnel shaped response of either of the log responses indicates a regressive environment. The $\log$ responses can also be interpreted to give structural information of the subsurface (Hesthammer and Fossen 1998; Trautwein-Bruns et al. 2011; Chattopadhyay and Ghosh 2006; Serra 1984). The dipmeter $\log$ response is very useful to identify faults. In a plot of dip versus azimuth, faults can be recognized by the variations in dip patterns, where the dip amount suddenly increases and then decreases as in a case of normal fault and vice versa in a reverse fault. From the same plot unconformities can be recognized by the sudden change or sudden reversal in the dip direction, while folds can be identified by the gradual changes in the dip direction and dip amount. Fractures and lineaments in the borehole can also be identified by image logging tools like Formation Micro Imaging (FMI), Borehole Televiewer (BHT), and Formation Micro Scanner (FMS) logging tools (Shahinpour 2013; Williams and Johnson 2004; Kabir et al. 2009). The image logging tools obtain a clear image of the borehole just like the core samples. The FMI and FMS imaging tools obtain images based on the variation of the resistivity values of the boreholes. The BHT tool uses the principle of reflection of acoustic waves of high frequency $(0.5-1.5 \mathrm{MHz})$ and obtains an image of the borehole based on the arrival times of the acoustic waves. The image logging tools though have a poor depth of penetration and are correlated with the structural information to obtain a better characterization of the reservoir and aid in the extraction process of the target reservoir.
Correlation of logs is done to match the lithology of a formation between two wells identified from the signatures of the log response. The log correlation gives a complete structural and stratigraphic information of the reservoir. The log signatures mimic the geophysical properties of the formation including geomachanical properties, electrical properties, and characterize lithology (Lukeš 2005; Luthi and Bryant 1997). Various techniques have been developed to correlate the $\log$ responses which include neural networks, cross-correlation algorithms with covariance measures, and using artificial intelligence with rule based systems. In the neural network based correlation techniques, the neurons are initially trained to identify a particular geologic marker for a given well and subsequently these are used to identify the markers in other wells. In the cross-correlation based well correlation techniques, the cross-correlation of raw well log data for corresponding logs between wells are done and a high correlation implies a correlation of strata (Dashtian et al. 2011). The artificial intelligence based techniques suffer from the drawback that it is not able to identify gaps and stretching of sequences which probably might be due to the presence of uncorrelated strata. To correlate the strata with the log response seismic data is used and a seismic to well tie is made by generating synthetic seismograms from the log data (Lorenzo and Hesselbo 1993; White and Simm 2003; Hampson-Russell 1999; Herrera and Van Der Baan 2012).

In this work we propose a novel method for stratigraphic correlation of wells, using discrete wavelet transform (DWT) and Fourier transform (FT) to identify stratigraphic interfaces, and using multi-scale analysis to characterize each interface. The fractal dimension of beds is found in this approach and the beds which have similar fractal dimensions are believed to characterize an independent strata, and based on this outlook the correlation between the wells is done. The feasibility of this technique is explained through synthetic examples and then tested on real data. The veracity of results is tested using seismic data between the wells using interpreted marker beds.

\section{Detection of stratigraphic interfaces}

Detection of stratigraphic interfaces can be visualized in the well log response by the sudden variation in the 
signal accompanying the log. These abrupt changes in the log response indicate sudden lithological changes in the concerned strata. Continuous wavelet transform (CWT) has been applied for bed boundary detection in the past (Vermaa et al. 2012; Choudhury et al. 2007). The advantage that CWT possesses over other techniques like fourier transform (FT) and Short Time Fourier Transform is that it gives good spatial and temporal resolution (Polikar 1996). The CWT analysis of the $\log$ response using a suitable mother wavelet is done through the variation of the scale factor $x$ and translation factor $y$ which complete the definition of the mother wavelet $\varphi((t-y) / x)$. This is defined in the following equation.

$W(x, y)=\frac{1}{\sqrt{|x|}} \int_{-\infty}^{\infty} f(t) \varphi\left(\frac{t-y}{x}\right) d t$

The wavelet coefficients $W(x, y)$ record the variations in the log response and presumed to occur due to lithological changes. In CWT analysis the mother wavelet is continuously shifted by changing the scale and translation factors. The scale factor is inversely proportional to the frequency of the signal. A high scale factor implies the lower frequency components are analyzed using the mother wavelet, whereas a low scale factor implies that the high frequency component of the signal are analyzed. The variation of the scale factor changes the shape of the mother wavelet. The translation factor controls the shifting of the mother wavelet which acts as a window function. Electrofacies association of well log signatures with core data has been done using CWT for studying the stratigraphy and deposition pattern (Perez-Muñoz et al. 2013; Panda et al. 2015) by varying the scale factor, and studying the wavelet coefficients of the well logs. But to validate this method it is very important to also have core data, as quiet often these changes do not have any geologic significance and are very misleading, especially when dealing with logs like gamma ray and SP which are more often very noisy. The noise here refers to the statistical nature of the $\log$ signatures. This method though promising fails to detect all the interfaces and does not give accurate depth information of all the interfaces, as demonstrated in this study through synthetic examples. Therefore we use discrete wavelet transform (DWT) and fourier transform (FT) to identify stratigraphic interfaces (Pan et al. 2008). DWT is used to denoise the log data and then it is analyzed using FT, and the various formation interfaces are consequently detected. In DWT analysis the variation of the scale factor is done as powers of 2 and not continuously which gives remarkable results (Yue et al. 2004). The DWT analysis gives coefficients called detail coefficients (CD) and approximation coefficients (CA) which correspondingly represent the high frequency component analysis and low frequency component analysis of the signal. In case of noisy signals the Approximation Coefficients are again operated by DWT to get another series of CA and CD. For reconstruction the Detail Coefficients are then inverse wavelet transformed. Mathematically they can be represented by the Eqs. 2, 3 and 4 .

$$
\begin{aligned}
& \mathrm{cA}_{y}^{0}=\sum_{t} f(t) \cdot \varphi(t-y) \\
& \mathrm{cD}_{y}^{j}=\sum_{t} \mathrm{~h}_{1(t-2 y)} \cdot \mathrm{cD}_{t}^{j-1} \\
& \mathrm{cA}_{y}^{j}=\sum_{t} \mathrm{~h}_{0(t-2 y)} \cdot \mathrm{cA}_{t}^{j-1} \\
& \mathrm{~h}_{0 y}=\frac{1}{\sqrt{ } 2} \int_{-\infty}^{\infty} \psi(t / 2) \psi^{\prime}(t-y) d t \\
& \mathrm{~h}_{1 y}=\frac{1}{\sqrt{ } 2} \int_{-\infty}^{\infty} \psi(t / 2) \psi^{\prime}(t-y) d t \\
& \mathrm{R}_{c D y}^{j}=\sum_{t} \mathrm{~h}_{1(t-2 y)}^{\prime} \cdot \mathrm{cD}_{t}^{j-1}
\end{aligned}
$$

The above equations highlights the process of the DWT analysis and the reconstruction of the denoised $\log$ response. Equation 2 explains the reconstruction process of the approximation coefficients, Eq. 3 elaborates on the reconstruction of the Detail Coefficients for level j, and Eq. 4 explains the reconstruction of the Approximation Coefficients for level j. Equations 6 and 7 denote weights which are used in defining the Approximation Coefficients and Detail Coefficients, respectively. The function $\psi$ is the scale function which is orthogonal to the mother wavelet. The signal can be reconstructed using Eq. 7 (Misiti et al. 2000; Yue et al. 2004; Boggess and Narcowich 2001), where $R_{c D}$ is the reconstructed detail coefficients. The Fourier transform of the reconstructed signal is then taken to identify the frequency spectrum of the signal. Only those frequency components are 
chosen which have maximum energy or amplitude, and are then inverse transformed and the variation of this resultant signal is used for detection of stratigraphic interfaces. The inflection points on the resultant signal when plotted, represent boundaries of the formation interfaces and correspondingly give their respective depths. The mother wavelet chosen for analysis was the Haar wavelet which gave superior results as compared to other wavelets and their families.

In our study we use only gamma ray logs and the flowchart highlighting the DWT and FT operation for identification of stratigraphic interfaces is shown in Fig. 1. The DWT operation works as a filtering operation and decomposes the signal into approximation coefficients (equivalent to low pass filtering) and detail coefficients (equivalent to high pass filtering). The mother wavelet used in this operation was the Haar wavelet. Since there is a large statistical variation in the gamma ray log equivalent to noise, the signal is denoised using a 3 level decomposition, after which the detail wavelet coefficients $\left(\mathrm{CD}_{3}\right)$ finally obtained are inverse transformed to get the reconstructed signal $R_{C D}$, which is used for spectrum analysis. The

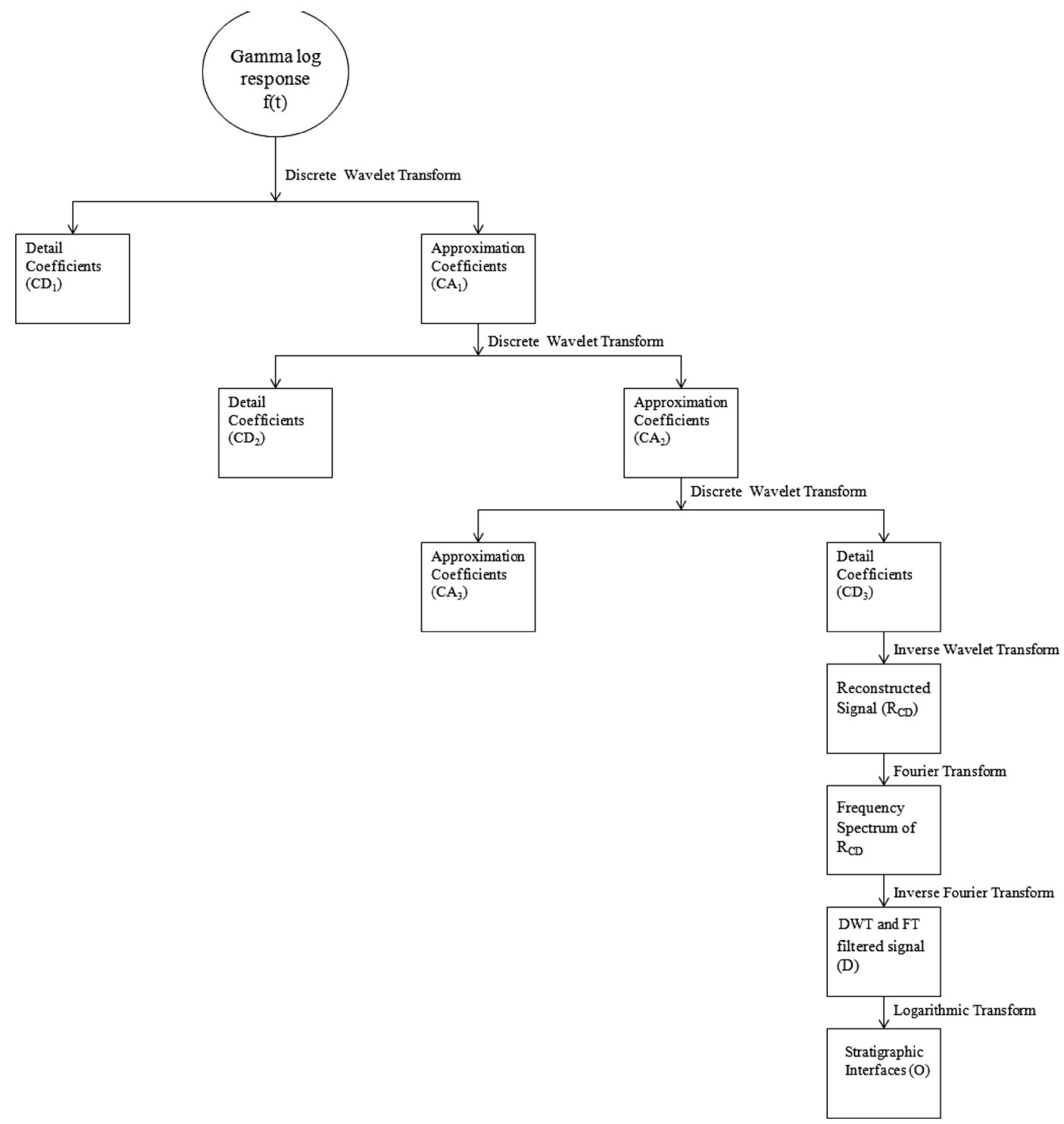

Fig. 1 The flowchart illustrating the steps involved in DWT and FT analysis of gamma ray logs 
decomposition level generally varies with the type of $\log$ signal used for analysis and is more for noisy signals like gamma ray logs, while even a single order decomposition is sufficient for less noisy signals. It is very important extract the Detail Coefficients from the signal, as they contain the high frequency components of the signal which has geologically crucial information and useful to identify thin and thick interfaces. If the log response is not denoised using DWT at its various decomposition levels, then it is very difficult to distinguish between signal and noise in the amplitude spectra when FT operations are done. The signal and noise in such situations have comparable strengths. Therefore when denoising using DWT operations, the sudden statistical fluctuations in the signal are eliminated and the stratigraphic formation signatures of the log response are better seen. A

Table 1 The design parameters for the synthetic log responses for well-1 and well-2

\begin{tabular}{|c|c|c|c|}
\hline S. no & Depth interval (m) & Thickness (m) & API \\
\hline \multicolumn{4}{|c|}{ Well-1 } \\
\hline 1 & 1248 & - & 130 \\
\hline 2 & $1248-1244$ & 4 & 87.77 \\
\hline 3 & $1244-1238$ & 6 & 122.2 \\
\hline 4 & $1238-1233$ & 5 & 128.8 \\
\hline 5 & $1233-1227$ & 6 & 119.9 \\
\hline 6 & $1227-1224$ & 3 & 11.64 \\
\hline 7 & $1224-1218$ & 6 & 96.44 \\
\hline 8 & $1218-1215$ & 3 & 125.7 \\
\hline 9 & $1215-1212$ & 3 & 61.11 \\
\hline 10 & $1212-1205$ & 7 & 114.2 \\
\hline \multicolumn{4}{|c|}{ Well-2 } \\
\hline 1 & 1258 & - & 130 \\
\hline 2 & $1258-1254$ & 4 & 87.8 \\
\hline 3 & $1254-1248$ & 6 & 122.2 \\
\hline 4 & $1248-1244$ & 4 & 128.9 \\
\hline 5 & $1244-1237$ & 7 & 119.9 \\
\hline 6 & $1237-1234$ & 3 & 11.59 \\
\hline 7 & $1234-1228$ & 6 & 96.48 \\
\hline 8 & $1228-1225$ & 3 & 125.7 \\
\hline 9 & $1225-1222$ & 3 & 61.2 \\
\hline 10 & $1222-1215$ & 7 & 114.2 \\
\hline 11 & $1215-1210$ & 5 & 127.2 \\
\hline 12 & $1210-1206$ & 4 & 46 \\
\hline 13 & $1206-1201$ & 5 & 81.75 \\
\hline
\end{tabular}

logarithmic transform is done at the end to the recovered signal $D$ after DWT and FT operations, after which we obtain signal $O$ which is used for stratigraphic interpretation.

\section{Multi-scale analysis}

The multi-scale analysis of geophysical data is a new concept that has been applied to many fields of geophysical signal analysis ranging from earthquake seismology (Dimri et al. 2005; Srivardhan and Srinu 2014), magnetotellurics (Telesca et al. 2012), electrical methods (Vedanti and Dimri, 2003), gravity and magnetic methods (Maus and Dimri, 1994; Maus and Dimri 1996; Fedi 2003; Fedi et al. 1997), reservoir characterization using well logs (Ouadfeul and Aliouane 2013, 2011), and exploration seismology (Ouadfeul and Aliouane 2012; Saraswat et al. 2014).

Fractal analysis is the study of macrostructure properties through microstructure studies. The properties are scale invariant and do not change by changing the scale of observation. Fractal dimension is a statistical index generally a non-integer, which tells us how the system becomes complex when the scale of observation changes. It measures the degree of irregularity when measured over multiple scales and determines how the fractals change from Euclidean objects. Multifractals are a group of fractals which have different fractal dimensions depending on the scale of observation (Mandelbrot 1983; Theiler 1990; Barnsley 2013; Voss 1991; Kaye 2008). The fractal dimension of geophysical signals can be found through many methods and can be broadly classified under various methods like box counting methods, power spectrum methods, divider relations, variograms, and area/perimeter methods (Klinkenberg 1994). In this study the fractal dimension has been calculated by multi-scale analysis using Continuous Wavelet Transform (Dimri et al. 2005; De Cola 1989), as explained in Eq. 1, and has been borrowed from studies done in earthquake seismology. The input well log signal was analyzed using a mother wavelet under various scales ranging from 1 to 8.4. The variation in scales was done in steps of 0.1 and the wavelet coefficients were found. A linear power law relationship between the variation of wavelet coefficients and the change in the scale factor was assumed. Since the 
Fig. 2 a The raw synthetic gamma ray $\log$ response of well-1. b The log response after DWT and FT operations from which stratigraphic interfaces can be identified at the inflection points for well-1
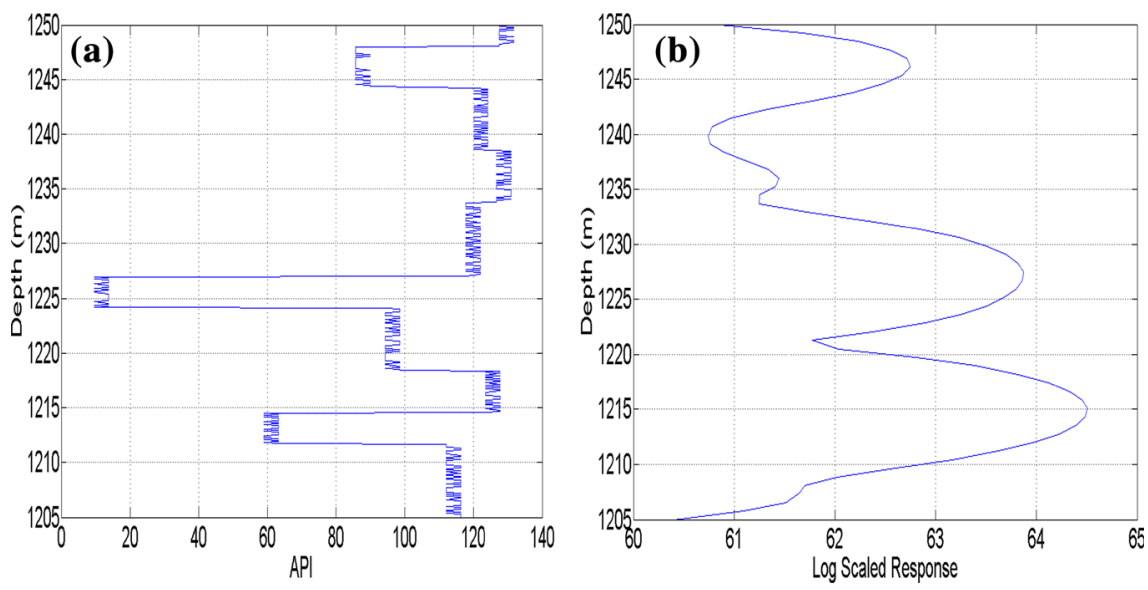

Fig. 3 a The raw synthetic gamma ray $\log$ response of well-2. b The log response after DWT and FT operations from which stratigraphic interfaces can be identified at the inflection points for well-2

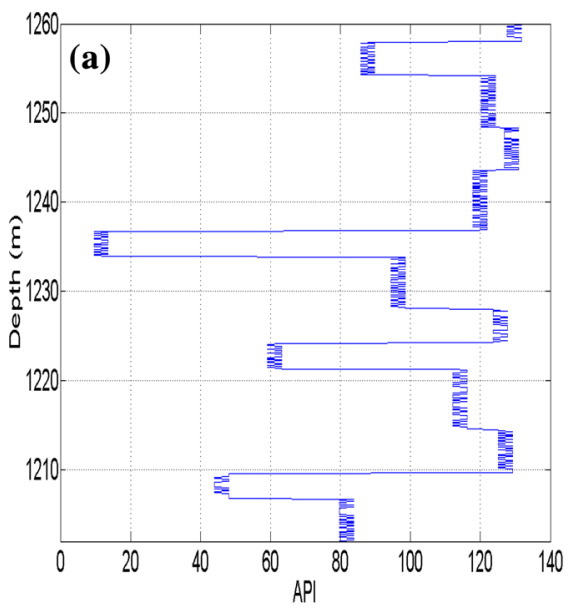

high scales represent the lower frequency variation of the signal, the upper limit of the scale range which gave good results was fixed at 4.4 through many trial and error observations. The variation of the wavelet coefficients $V_{\mathrm{cw}}$ with scale factor x gave a straight line on a log-log plot whose slope gave the value of Holder Exponent $H$ which is related to the fractal dimension D as demonstrated in Eqs. 8 and 9. The mother wavelet selected for analysis was the Daubechies family of wavelets of order $2(\mathrm{db} 2)$ which gave good results. Other wavelets like the Symlets, Coiflets, Haar, and Morlet family of wavelets and their orders were also tried, but the db2 wavelet gave good results.

$V_{c w} \sim x^{H}$

$2 D=5-H$
If the upper limit of the scale range selected is further extended, then there is significant deviation observed on the plot characterized by Eq. 8. At large scale values there is significant deviation from the power law relation which we assume, and the interval is correspondingly adjusted such that the power law relation defined by the equation is maintained. Each stratigraphic interface identified using DWT and FT analysis is characterized by a fractal dimension and wells can be easily correlated depending on this value.

\section{Synthetic signal}

Synthetic gamma ray log signals were generated for two wells namely well-1 and well-2. Synthetic gamma ray logs were prepared as they are most commonly 
Table 2 The actual and derived depths of the stratigraphic interfaces and their corresponding fractal dimensions for well-1 and well-2

\begin{tabular}{|c|c|c|c|c|}
\hline S. no. & Actual depth (m) & Thickness (m) & Derived depth $(\mathrm{m})$ & Fractal dimension \\
\hline \multicolumn{5}{|l|}{ Well-1 } \\
\hline 1 & 1205 & - & 1205 & 1.5023 \\
\hline 2 & 1212 & 7 & 1213 & 1.5869 \\
\hline 3 & 1215 & 3 & 1215 & 1.5654 \\
\hline 4 & 1218 & 3 & 1217 & 1.5250 \\
\hline 5 & 1224 & 6 & 1224 & 1.6166 \\
\hline 6 & 1227 & 3 & 1226 & 1.5789 \\
\hline 7 & 1233 & 6 & 1232 & 1.4383 \\
\hline 8 & 1238 & 5 & 1239 & 1.5169 \\
\hline 9 & 1244 & 6 & 1245 & 1.5108 \\
\hline 10 & 1248 & 4 & 1248 & 1.5056 \\
\hline \multicolumn{5}{|c|}{ Well-2 } \\
\hline 1 & 1201 & - & 1201 & 1.5569 \\
\hline 2 & 1206 & 5 & 1208 & 1.3395 \\
\hline 3 & 1210 & 4 & 1210 & 1.5312 \\
\hline 4 & 1215 & 5 & 1212 & 1.5112 \\
\hline 5 & 1222 & 7 & 1223 & 1.5959 \\
\hline 6 & 1225 & 3 & 1224 & 1.5701 \\
\hline 7 & 1228 & 3 & 1228 & 1.5233 \\
\hline 8 & 1234 & 6 & 1233 & 1.6090 \\
\hline 9 & 1237 & 3 & 1236 & 1.5802 \\
\hline 10 & 1244 & 7 & 1242 & 1.4176 \\
\hline 11 & 1248 & 4 & 1247 & 1.5175 \\
\hline 12 & 1254 & 6 & 1254 & 1.5281 \\
\hline 13 & 1258 & 4 & 1258 & 1.5214 \\
\hline
\end{tabular}

Table 3 The depth of the target formations existing between wells F02-1 and F03-4

\begin{tabular}{lc}
\hline Formation & TVDSS (m) \\
\hline Well F02-1 & \\
Truncation 1 & 995.56 \\
FS4 & 1065.27 \\
Well F03-4 & \\
Truncation 1 & 634.46 \\
FS4 & 914.76 \\
\hline
\end{tabular}

used in stratigraphic interpretation. The synthetic response was prepared for interfaces whose thickness and API values are detailed in Table 1. The layers which have a API value of less than 20 can be considered to be clean sand zones. Layers whose API values are greater than 80 can be considered to be pure shale zones. Intermediate values can be mixed shalesand zones. The synthetic response were prepared by adding a $20 \%$ random noise to the original signal (API value) characterizing the synthetic anomaly. The noise here refers to statistical fluctuations in the synthetic signal and was taken to vary up to $\pm 20 \%$ of the mean value of the signal, characterizing a particular interface. The depth interval for well-1 was $50 \mathrm{~m}$, whereas the depth interval for well-2 was $60 \mathrm{~m}$. The stratigraphic interfaces were successfully identified using DWT and FT operations and were plotted in Figs. 2 and 3 for both the wells respectively. A multiscale CWT analysis was also performed on both the wells and plotted in Figs. 6 and 7 respectively. The scale factor for this analysis was varied between 1 and 30 in steps of 1 for well- 1 and 1 to 35 for well- 2 in steps of 1 respectively. The analysis was done using four commonly used mother wavelets, namely Haar, Daubechies 2, Gauss 1, and Morlet. The fractal 
Table 4 The predicted depths of the stratigraphic interfaces and their corresponding fractal dimensions for wells F02-1 and F03-4

\begin{tabular}{|c|c|c|c|}
\hline S. no. & Bed boundaries (m) & Thickness (m) & Fractal dimension \\
\hline \multicolumn{4}{|c|}{ Well F02-1 } \\
\hline 1 & 619.95 & - & 1.4619 \\
\hline 2 & 667.50 & 47.55 & 1.3651 \\
\hline 3 & 694.93 & 27.43 & 1.5127 \\
\hline 4 & 730.14 & 35.21 & 1.4973 \\
\hline 5 & 787.29 & 57.15 & 1.4961 \\
\hline 6 & 837.43 & 50.14 & 1.5054 \\
\hline 7 & 879.03 & 41.60 & 1.4903 \\
\hline 8 & 911.34 & 32.31 & 1.4750 \\
\hline 9 & 944.87 & 33.53 & 1.5191 \\
\hline 10 & 995.01 & 50.14 & 1.4682 \\
\hline 11 & 1034.94 & 39.92 & 1.5216 \\
\hline 12 & 1062.37 & 27.43 & 1.4680 \\
\hline 13 & 1087.37 & 25.00 & 1.4943 \\
\hline \multicolumn{4}{|c|}{ Well F03-4 } \\
\hline 1 & 632.58 & - & 1.4598 \\
\hline 2 & 682.44 & 49.86 & 1.4510 \\
\hline 3 & 750.13 & 67.69 & 1.4541 \\
\hline 4 & 812.29 & 62.16 & 1.4963 \\
\hline 5 & 862.28 & 49.99 & 1.4973 \\
\hline 6 & 887.27 & 24.99 & 1.5090 \\
\hline 7 & 912.57 & 25.3 & 1.4679 \\
\hline 8 & 937.56 & 24.99 & 1.5029 \\
\hline 9 & 962.40 & 24.84 & 1.5688 \\
\hline 10 & 997.45 & 35.05 & 1.4831 \\
\hline 11 & 1035.1 & 37.65 & 1.5510 \\
\hline 12 & 1060.09 & 24.99 & 1.4826 \\
\hline 13 & 1082.50 & 22.41 & 1.5053 \\
\hline
\end{tabular}

dimensions were calculated based on the depth information of the various interfaces, obtained using DWT and FT analysis and was tabulated in Table 2.

\section{Case study}

The well data was taken from the Netherlands Offshore F3 Block, with surveys undertaken by dGB Earth Sciences (https://opendtect.org/osr/pmwiki.php/ Main/NetherlandsOffshoreF3BlockComplete4GB). The block was explored using 3D seismic and well log surveys for the presence of hydrocarbons. The datasets have been processed and interpreted using software OpendTect by dGB Earth Sciences and is available for viewing and further processing in the public domain.
Geological studies for the entire basin has been undertaken and many characteristic formations have been identified. The formations which extend between the two wells namely F02-1 and F03-4 needs to be ascertained and gamma ray log responses were (commonly used in stratigraphic interpretation) taken for both the wells and correlated using an interpreted seismic slice in OpendTect which was present in between both the wells. The logs have a sampling interval of $0.152 \mathrm{~m}$. The depth interval selected for this study was taken between 600.145 and $1100.02 \mathrm{~m}$ (TVDSS) for well F02-1 and 600.151 and $1100.02 \mathrm{~m}$ (TVDSS) for well F03-4. Tracking of formations was performed and there were 2 formations namely FS4 and Truncation 1 which were continuous and extended between both the wells, as shown in Fig. 8. Their 

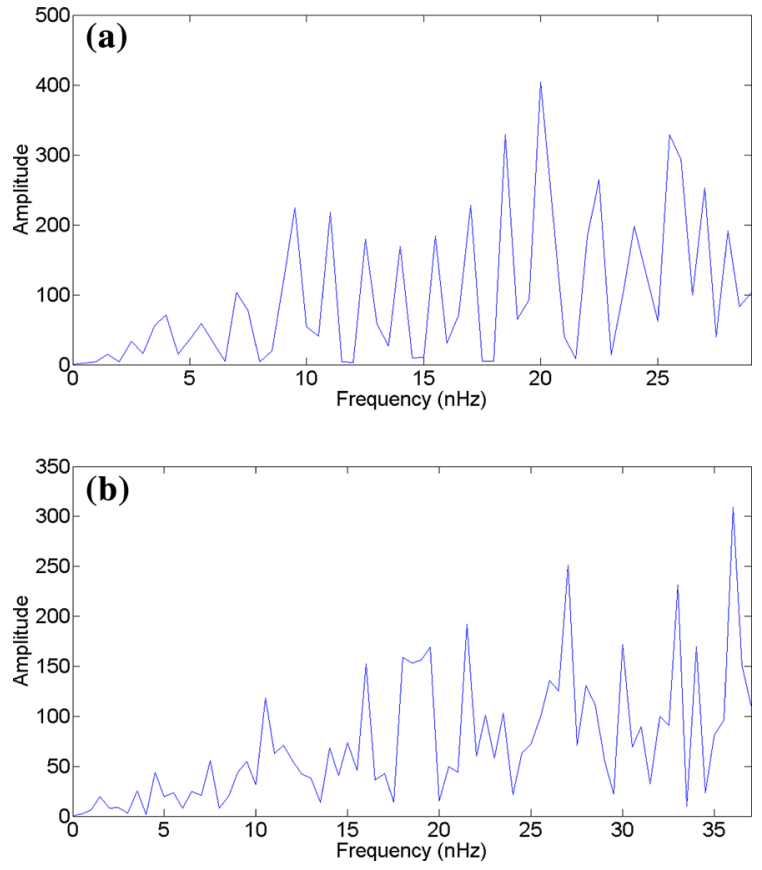

Fig. 4 a Power spectrum of the reconstructed signal for well-1. b Power spectrum of the reconstructed signal for well-2
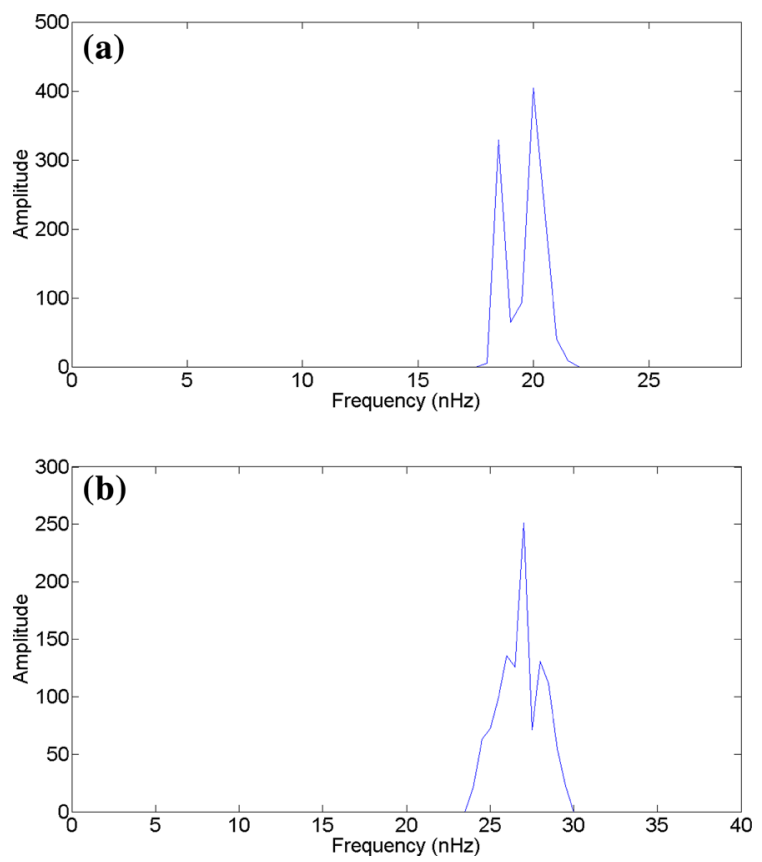

Fig. 5 a Frequency range selected for well-1. b Frequency range selected for well-2 corresponding depths are tabulated in Table 3. Using the gamma ray $\log$ responses the various stratigraphic interfaces for both the wells were found with DWT and FT analysis, which were then analyzed to find the fractal dimensions. The various formation interfaces were correlated using the obtained fractal dimension values and the results are tabulated in Table 4.

\section{Discussion of results}

The DWT and FT based analysis of the well $\log$ signals were successfully applied to synthetic and real gamma ray log data. The analysis was first done on synthetic datasets for two synthesized wells. For noisy gamma ray $\operatorname{logs}$ the $\mathrm{db} 1$ wavelet was chosen with a $3^{\text {rd }}$ order decomposition level, using the Haar wavelet. After a first order decomposition, the obtained $\mathrm{CA}_{1}$ coefficients were again DWT analyzed and the second order Approximation Coefficients $\mathrm{CA}_{2}$ were again DWT analyzed to get the third order detail coefficients $\mathrm{CD}_{3}$, which were then inverse transformed using inverse wavelet transform to get the reconstructed signal. The raw signal is plotted Figs. $2 \mathrm{a}$ and $3 \mathrm{a}$ for both the wells respectively. The reconstructed signal was then FT analyzed and the amplitude spectrum of the log response are seen in Fig. 4a, b. Only those parts of the spectrum were selected for further analysis that had maximum amplitude as shown in Fig. 5a, b, which were then inverse Fourier transformed, to get the response $\mathrm{D}$. The amplitude scale of the response $\mathrm{D}$ was then logarithmically transformed as given by Eq. 10 (Jang and Jang 2003), for obtaining a smooth response and plotted in Figs. $2 \mathrm{~b}$ and $3 \mathrm{~b}$ respectively. It can be seen that the inflection points on the signal when correlated with the log signal, gives the corresponding depth of the various stratigraphic interfaces as tabulated in Table 2. The derived depth of the stratigraphic interfaces are picked from the inflection points and tabulated. The results are compared with actual depths of the formations which were selected when designing the synthetic signal. The results of the detection of the various formation interfaces have a good match with the actual depths as evident from Table 2 respectively. Based on the interfaces detected from the DWT and FT analyzed reconstructed log signal the fractal dimensions were found. These are also tabulated in Table 2. The variation in scale parameter was done through trial and error method and was varied between 
(a)

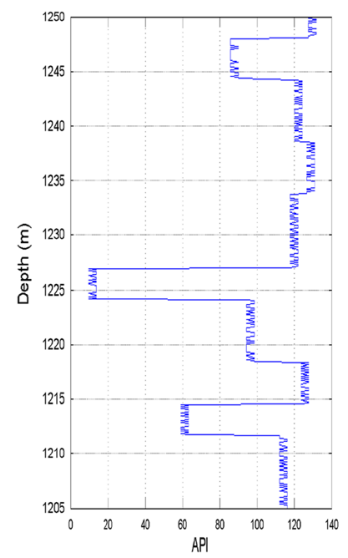

(c)

(b)

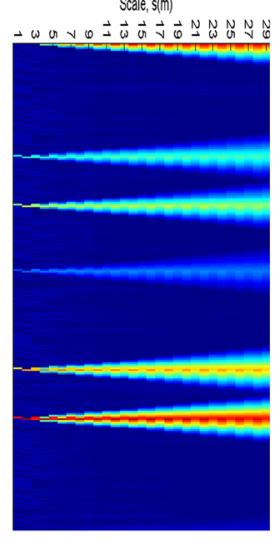

1 (d)

Scale, $s(\mathrm{~m})$

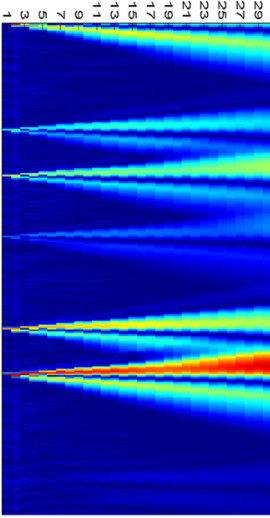

Sales $\{(m i)$

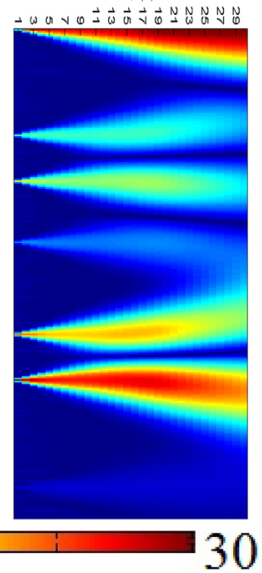

(e)

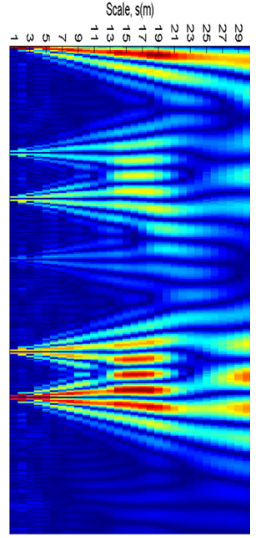

Fig. 6 a The synthetic log response of well-1. Scalogram responses of b Haar (1-30), c Daubechies 2 (1-30), d Gauss 1 (1-30), e Morlet (1-30)

(a)

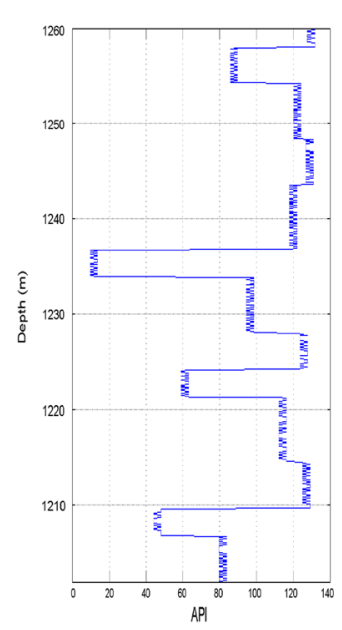

(b) sale s(m)

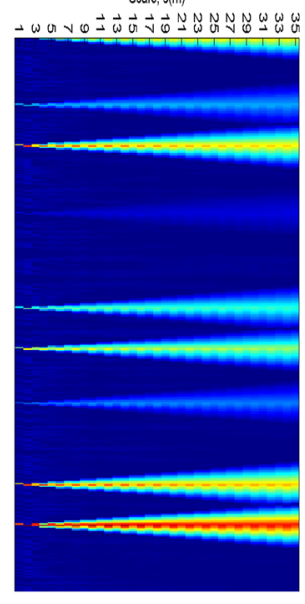

1 (c) scales sm)

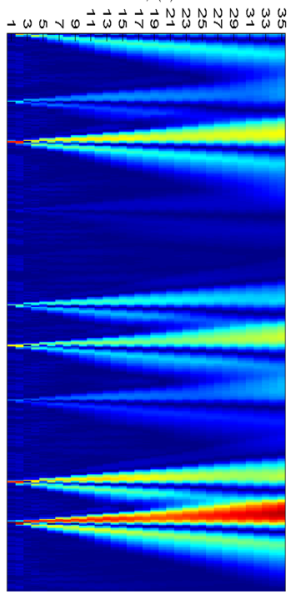

(d) Sage sin

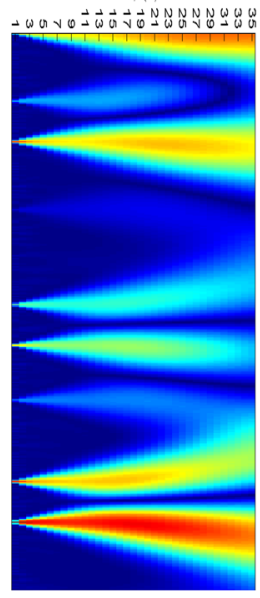

(e) Somes sm

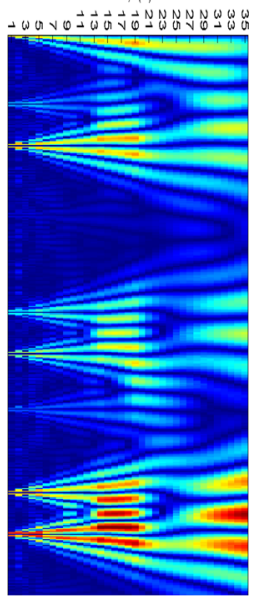

\section{5}

Fig. 7 a The synthetic log response of well-2. Scalogram responses of b Haar (1-35), c Daubechies 2 (1-35), d Gauss 1 (1-35), e Morlet (1-35)

1 and 4.4 in steps of 0.1 for the synthetic data, using the $\mathrm{db} 2$ wavelet. The results show that based on the obtained values, the beds 1-9 correlate with beds 4-12 for well-1 and well-2 respectively. The depths which are predicted and derived are from DWT and FT analysis are very accurate with an error of $\pm 1 \mathrm{~m}$.

$A=\log 2\left(\frac{D}{440}\right)+69$
The synthetic datasets were also subjected to a CWT analysis to find out the stratigrapic interfaces, and the results of the analysis are shown in Figs. 6 and 7 , respectively for both the wells. The plot is a scalogram of the wavelet coefficients for 4 commonly used mother wavelets namely Haar, Daubechies 2, Gauss 1, and Morlet. The scale range used in the analysis was between 1-30 for well-1 and 1-35 for 
Fig. 8 The stratigraphic correlation of gamma ray $\log$ response for wells F02-1 and F30-4 through an interpreted seismic section present between the two wells. The blue line represents the FS4 formation. The green line represents the Truncation 1 formation and the yellow line is its linearly interpolated path
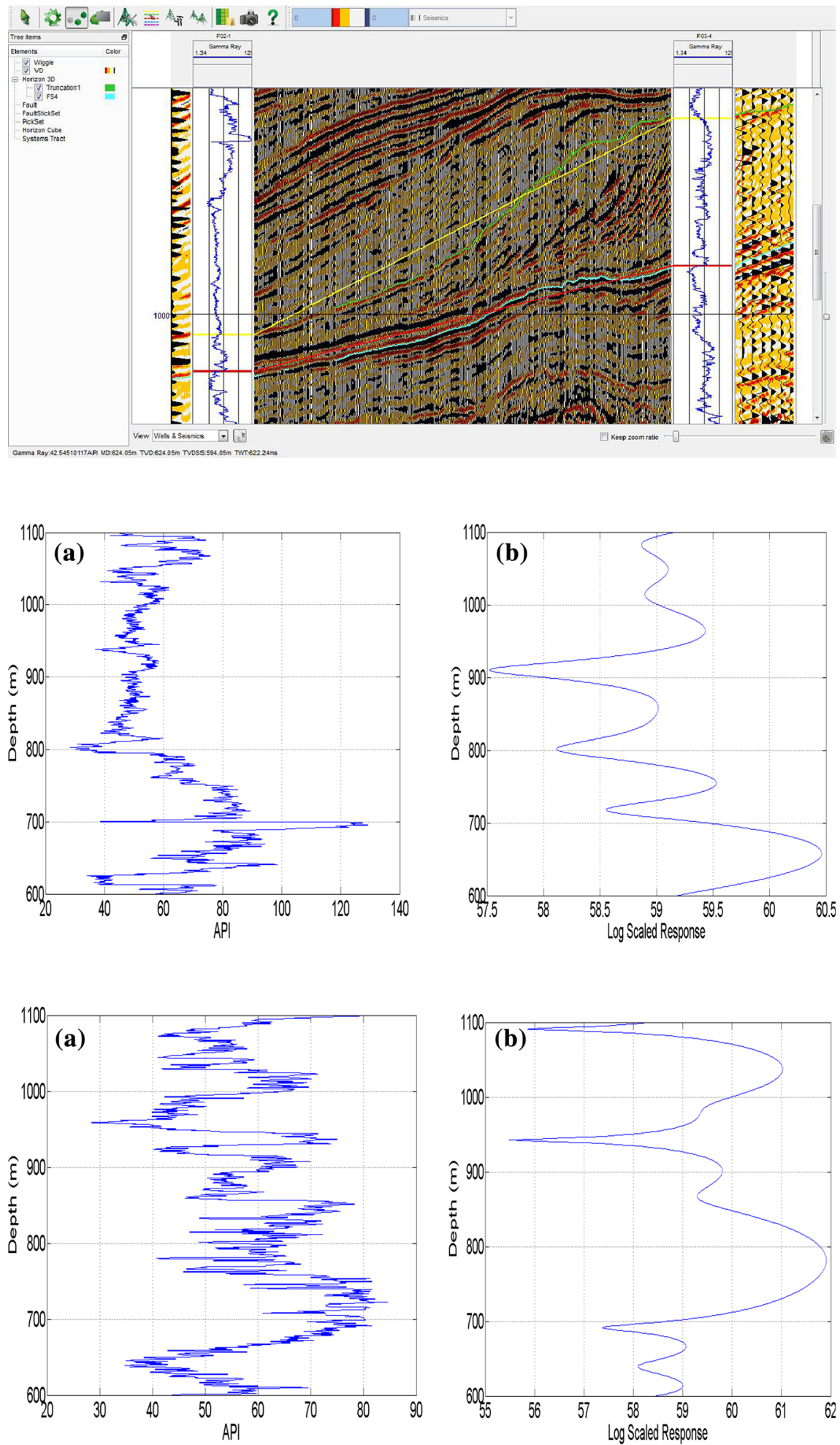

Fig. 10 a The raw synthetic gamma ray log response of well F03-4. b The log response after DWT and FT operations from which stratigraphic interfaces can be identified at the inflection points for well F03-4
Fig. 9 a The raw synthetic gamma ray log response of well F02-1. b The log response after DWT and FT operations from which stratigraphic interfaces can be identified at the inflection points for well F02-1 

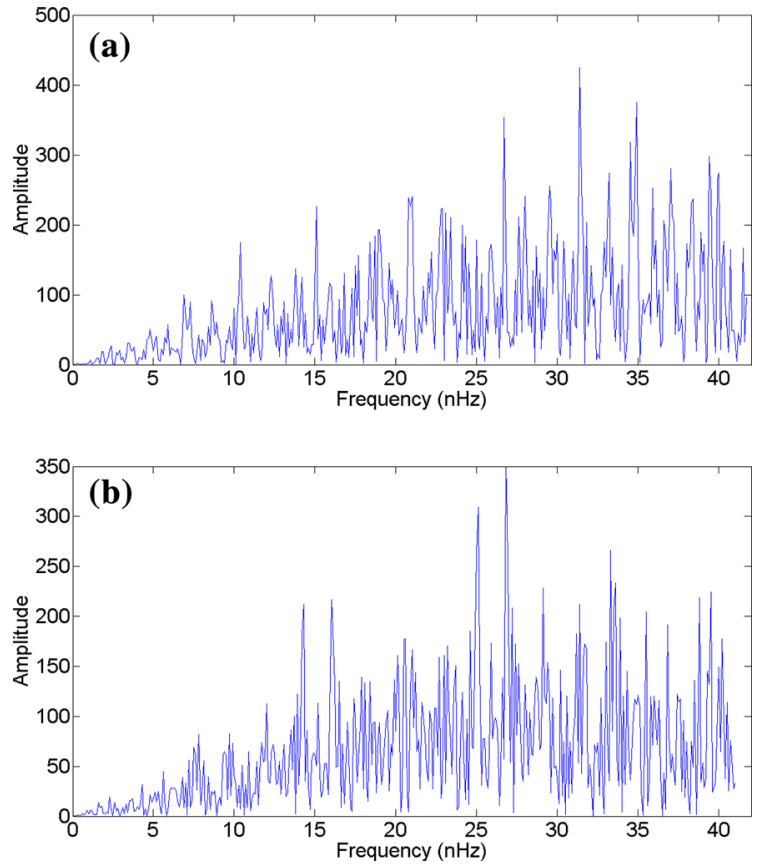

Fig. 11 a Power spectrum of the reconstructed signal for well F02-1. b Power spectrum of the reconstructed signal for well F03-4
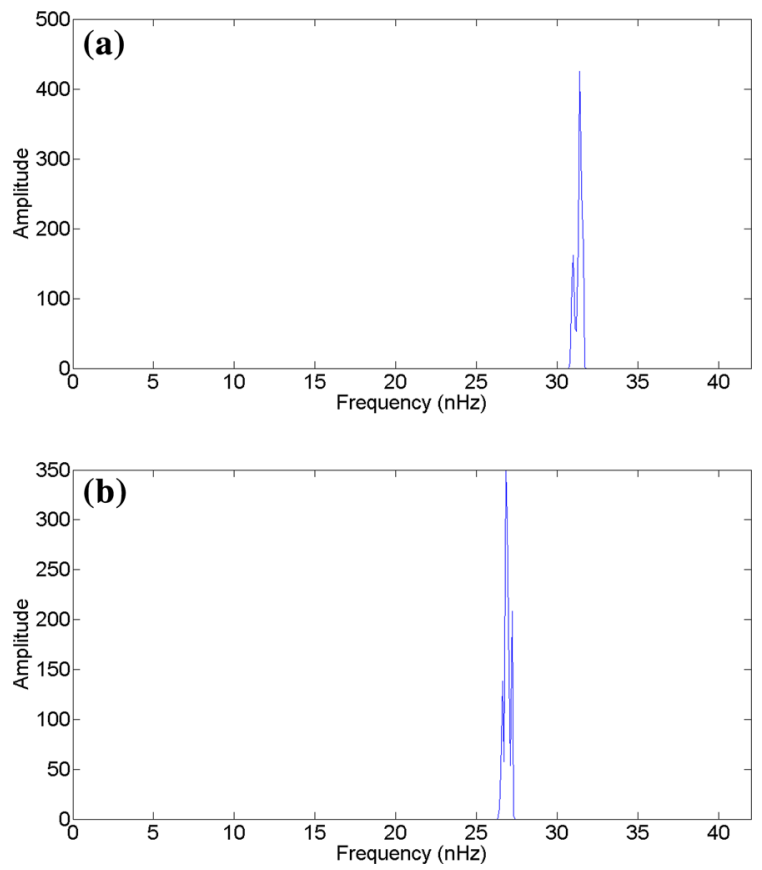

Fig. 12 a The frequency range selected for well F02-1. b The frequency range selected for well F03-4 well-2 respectively in steps of 1 . In the scalogram, the center of the cone of influence indicates the depth of the corresponding interface. The results of well- 1 for the Haar wavelet shows that it is successful in deciphering some of the bed boundaries, but fails to detect all of them. The interface at depth 1244 and $1205 \mathrm{~m}$ is not deciphered. There is a very faint signature obtained for the interface present at $1227 \mathrm{~m}$. Also the interfaces at depths 1233 and $1227 \mathrm{~m}$ are not accurately predicted. This is similar with the Daubechies 2 and the Gauss 1 wavelets as well for the same scale range, whereas the Morlet wavelet also seems to give the same results but it is very difficult to find the center of the cone of influence in this wavelet which gives the accurate depth of the interfaces in the chosen scale range. The results of well-2 are also somewhat similar for all the 4 wavelets. The Haar wavelet is successful in deciphering all the interfaces, except for the ones at depths 1206 and $1237 \mathrm{~m}$. Also the signatures from interfaces at depths 1224 and $1244 \mathrm{~m}$ are very weak and not convincing. Therefore it is necessary to have a core data to corroborate the results in such cases and the results based on CWT analysis alone cannot be used for stratigraphic interpretation and correlation of wells. This is similar for the other 3 wavelets as well. The Haar wavelet though performs the best when compared with other wavelets.

The data from wells F02-1 and F03-4 were correlated after interpreting the seismic section between them as shown in Fig. 8, and the results are tabulated in Table 3. Only two formations namely Truncation 1 and FS4 correlate between the wells through the seismic section, for the given depth interval. The log data for the two wells between the depth interval 600-1100 m TVDSS were selected and were denoised using DWT and FT operations. The raw $\log$ signals for both the wells are shown in Figs. 9a and 10a respectively. The Haar wavelet was used in the DWT operation with a 3 level decomposition. The power spectrum of the reconstructed signal were then plotted in Fig. 11a, b and only those responses that had maximum amplitude or power were selected as shown in Fig. 12a, b. The selected response was then inverse transformed and logarithmically scaled using Eq. 10 and plotted in Figs. $9 \mathrm{~b}$ and $10 \mathrm{~b}$ respectively. The depth of the derived stratigraphic interfaces were picked at the inflection points from Figs. 9c and 10c and tabulated in Table 4. Based on 
the stratigraphic interfaces detected, the fractal dimensions were correspondingly found and tabulated. It is important to interpret the table only after knowing the general geological trend of the area, as blind interpretation can lead to absurd results. Therefore from the seismic section in Fig. 8 it can be inferred that the beds dip downward as we move from well F03-4 to F02-1. As a result from Table 4 it can be concluded that based on the values of the fractal dimensions, the bed 1 of well F03-4 corresponds to bed 10 in well F02-1, and bed 7 in well F03-4 corresponds to bed 12 in well F02-1. The depths obtained for the two beds shows good agreement with those obtained using the interpreted seismic data (Table 3) present between the wells.

\section{Conclusion}

The correlation of stratigraphic interfaces between two wells using Discrete Wavelet Transform and Fourier Transform through a multi-scale analysis was demonstrated. The technique was first demonstrated using synthetic gamma ray logs with an error of $\pm 1 \mathrm{~m}$ and was then applied to real data belonging the offshore F3 Block in the North Sea. This technique was proved to be superior to methods using only Continuous Wavelet Transform with a multi-scale analysis, as the later fails to detect all the interfaces and does not give the correct depth information of the interfaces. Also the later requires core data, using which one can corroborate the obtained results and it is also difficult to choose the right wavelet and the right scale range for analysis. The proposed technique is able to overcome these challenges and also characterizes each interface with a numerical fractal dimension value which can be easily used to correlate between wells. The technique though requires seismic data to be present to corroborate results which is very much required to find out the continuity of horizons. This study demonstrates that the proposed technique is very much accurate and can be used for stratigraphic correlation of wells.

Acknowledgments I wish to thank dGB Earth Sciences for providing the dataset and the processing software OpendTect for the completion of this work. I also wish to thank my anonymous reviewers whose comments and suggestions greatly improved the quality of this manuscript.

\section{References}

Barnsley MF (2013) Fractals Everywhere, New edition. Courier Dover Publications, New York

Boggess A, Narcowich FJ (2001) A first course in wavelets with Fourier analysis. Prentice-Hall, Englewood Cliffs, p 283

Chattopadhyay T, Ghosh DK (2006) Structural interpretation of dipmeter log: a case study from Baramura field of Tripura. The 6th International Conference \& Exposition on Petroleum Geophysics, Kolkata

Choudhury S, Chandrasekhar E, Pandey VK, Prasad M (2007) Use of wavelet transformation for geophysical well-log data analysis. In: 2007 15th international conference on digital signal processing. IEEE, pp 647-650

Dashtian H, Jafari GR, Lai ZK, Masihi M, Sahimi M (2011) Analysis of cross correlations between well logs of hydrocarbon reservoirs. Transp Porous Media 90(2): 445-464

De Cola L (1989) Multi-scale data models for spatial analysis, with applications to multifractal phenomena. In AutoCarto 9: ninth international symposium on computer-assisted cartography, Baltimore, Maryland, April 2-7, vol 9. The Society, p 313

Dimri VP, Vedanti N, Chattopadhyay S (2005) Fractal analysis of aftershock sequence of the Bhuj earthquake: a waveletbased approach. Curr Sci 88(10):1617-1620

Ellis D (1987) Well logging for earth scientists. Elsevier, New York. ISBN 0-444-01180-3

Fedi M (2003) Global and local multi-scale analysis of magnetic susceptibility data. Pure Appl Geophys 160:2399-2417

Fedi M, Quarta T, Santis AD (1997) Inherent power-law behavior of magnetic field power spectra from a Spector and Grant ensemble. Geophysics 62:1143-1150

Hampson-Russell (1999) Theory of the Strata program: Technical Report May 1999, CGGVeritas Hampson-Russell

Herrera RH, Van Der Baan M (2012) Automated seismic-towell ties using dynamic time warping. GeoConvention: Vision, Canada

Hesthammer J, Fossen H (1998) The use of dipmeter data to constrain the structural geology of the Gullfaks Field, northern North Sea. Mar Pet Geol 15(6):549-573

Igbokwe OA (2011) Stratigraphic interpretation of Well-Log data of the Athabasca Oil Sands of Alberta Canada through Pattern recognition and Artificial Intelligence. Dissertation submitted for Master of Science, Institute for Geoinformatics (ifgi), Munster, Germany

Jang JSR, Jang YS (2003) Microcontroller implementation of melody recognition: a prototype. In: Proceedings of the 11th ACM international conference on multimedia, Berkeley, CA, USA, pp 452-453

Kabir S, Rivard P, He DC, Thivierge P (2009) Damage assessment for concrete structure using image processing techniques on acoustic borehole imagery. Constr Build Mater 23(10):3166-3174

Kaye BH (2008) A random walk through fractal dimensions. Wiley, New York

Klinkenberg B (1994) A review of methods used to determine the fractal dimension of linear features. Math Geol 26(1):23-46 
Li S, Henderson CM, Stewart RR (2014) Well log study and stratigraphic correlation of the Cantuar Formation, southwestern Saskatchewan, Crewes Research Report-Volume 16

Lorenzo JM, Hesselbo SP (1993) 16. Seismic-to-well correlation of seismic unconformities at leg 150 continental slope sites1. In: Proceedings of the ocean drilling program: scientific results, vol 150. The Program, p 293

Lukeš J (2005) Methods of well logging used for borehole correlation in the granite stock, Podlesí granite, Bohemian Massif. Bull Geosci 80(2):155-161

Luthi SM, Bryant ID (1997) Well-log correlation using a backpropagation neural network. Math Geol 29(3):413-425

Mandelbrot BB (1983) The fractal geometry of nature (vol 173). Macmillan, London

Maus S, Dimri VP (1994) Fractal properties of potential fields caused by fractal sources. Geophys Res Lett 21:891-894

Maus S, Dimri VP (1996) Depth estimation from the scaling power spectrum of potential field. Geophys J Int 124: $113-120$

Misiti M, Misiti Y, Oppenheim G, Poggi JM (2000) Wavelet Toolbox for Use with MATLAB User's Guide. The Math Works Inc., Natick, p 572

Mory AJ, Iasky RP (1996) Stratigraphy and structure of the onshore northern Perth Basin, Western Australia, vol 46. Geological Survey of Western Australia, East Perth

Ouadfeul S, Aliouane L (2011) Multifractal analysis revisited by the continuous wavelet transform applied in lithofacies segmentation from well-logs data. Int J Appl Phys Math 1(1):10-18

Ouadfeul SA, Alioaune L (2012) Fractal analysis revisited by the continuous wavelet transform of AVO seismic data. Arab J Geosci 5:1469-1474

Ouadfeul S, Aliouane L (2013) Automatic lithofacies segmentation suing the wavelet transform modulus maxima lines (WTMM) combined with the detrended fluctuations analysis (DFA). Arab J Geosci 6(3):625-634

Pan SY, Hsieh BZ, Lu MT, Lin ZS (2008) Identification of stratigraphic formation interfaces using wavelet and Fourier transforms. Comput Geosci 34(1):77-92

Panda SC, Srivardhan V, Chatterjee R (2015) Lithological characteristics analysis in stratton oil field using wavelet transform. In: 77th EAGE conference and exhibition 2015

Perez-Muñoz T, Velasco-Hernandez J, Hernandez-Martinez E (2013) Wavelet transform analysis for lithological characteristics identification in siliciclastic oil fields. J Appl Geophys 98:298-308

Polikar R (1996). The wavelet tutorial
Saraswat P, Raj V, Sen MK, Narayanan A (2014) Multiattribute seismic analysis with fractal dimension and 2D and 3D continuous wavelet transform. SPE Reservoir Eval Eng 17(04):436-443

Serra O (1984) Fundamentals of well log interpretation 1. The acquisition of logging data. Elsevier, Amsterdam

Shahinpour A (2013). Borehole image log analysis for sedimentary environment and clay volume interpretation

Srivardhan V, Srinu U (2014) Potential of fractal analysis of earthquakes through wavelet analysis and determination of b value as an aftershock precursor: a case study using earthquake data between 2003 and 2011 in Turkey. J Earthq. doi:10.1155/2014/123092

Telesca L, Lovallo M, Hsu HL, Chen CC (2012) Analysis of site effects in magnetotelluric data by using the multifractal detrended fluctuation analysis. J Asian Earth Sci 54:72-77

Theiler J (1990) Estimating fractal dimension. JOSA A 7(6): $1055-1073$

Trautwein-Bruns U, Hilgers C, Becker S, Urai JL, Kukla PA (2011) Fracture and fault systems characterising the intersection between the Lower Rhine Embayment and the Ardennes-Rhenish Massif-results from the RWTH-1 well, Aachen, Germany [Bruch-und Störungssysteme in der Übergangszone zwischen der Niederrheinischen Bucht und dem Rheinischen Schiefergebirge im belgisch-deutschen Grenzbereich-Ergebnisse der Bohrung RWTH-1, Aachen, Deutschland]. Zeitschrift der Deutschen Gesellschaft für Geowissenschaften 162(3):251-275

Vedanti N, Dimri VP (2003) Fractal behavior of electrical properties in oceanic and continental crust. Indian J Marine Sci 32(4):273-278

Vermaa AK, Cheadlea BA, Mohanty WK, Routrayc A, Mansinhaa L (2012) Detecting stratigraphic discontinuities using wavelet and s-transform analysis of well log data. In: GeoConvention 2012: Vision

Voss RF (1991) Random fractals: characterization and measurement. In: Pynn R, Skjeltorp A (eds) Scaling phenomena in disordered systems. Springer, New York, pp 1-11

White RE, Simm R (2003) Tutorial: Good practice in well ties. First Break 21(10):75-83

Williams JH, Johnson CD (2004) Acoustic and optical boreholewall imaging for fractured-rock aquifer studies. J Appl Geophys 55(1):151-159

Yue WZ, Tao G, Liu ZW (2004) Identifying reservoir fluids by wavelet transform of well logs. In: Proceedings of the SPE Asia Pacific oil and gas conference and exhibition, Perth, Australia (SPE 88559) 